\title{
Participação econômica das atividades de subsistência na agricultura familiar
}

\author{
RAQUEL BREITENBACH \\ Instituto Federal de Educação, Ciência e Tecnologia do Rio \\ Grande do Sul
}

\begin{abstract}
Resumo
O presente artigo compreende um Estudo de Casos Múltiplos acerca da importância econômica das atividades de subsistência para a agricultura familiar de duas regiões do Rio Grande do Sul. O Brasil possui características diversas quando o assunto é agricultura. Dentre essa diversidade, destaca-se com importância social e econômica a agricultura familiar, que engloba um percentual significativo da população no campo, gerando emprego e renda. Porém, essa agricultura familiar é heterogênea, já que dentro de um mesmo estado, como o caso do Rio Grande do Sul. Existe uma diversidade de situações nesse setor e, de modo especial estudado neste trabalho, essa diversidade pode refletir nas atividades de subsistência e na sua participação econômica distinta. Para tanto, este estudo levantou dados empíricos em duas distintas regiões do Estado, Missões e Norte, visando identificar características que distinguem a agricultura familiar das duas realidades. 0 objetivo do estudo foi identificar a participação econômica das atividades de subsistência comparativamente com as atividades comerciais da agricultura familiar de Dezesseis de Novembro (Região Missões) e Sertão (Região Norte) no Rio Grande do Sul, identificando fatores de heterogeneidade do setor. Para que o estudo fosse possível, foram selecionadas cinco unidades de produção agropecuária familiares representativas do setor em cada município. Como principal resultado, destaca-se que as atividades de subsistência são desenvolvidas em maior número e têm maior participação econômica, se comparadas às atividades comerciais, na agricultura familiar de Dezesseis de Novembro do que na de Sertão.
\end{abstract}

Palavras-Chave: Agricultura Familiar. Heterogeneidade. Comercialização. Desenvolvimento Econômico

\section{Economic participation of subsistence activities in family farm}

\begin{abstract}
This article comprises a Multiple Case Study on the economic importance of subsistence activities for family farms of Rio Grande do Sul Brazil has different characteristics when it comes to agriculture. Among this diversity, it stands out with social and economic importance of family farming, which encompasses a significant percentage of the population in the country, generating jobs and income. However, this family farm is heterogeneous, causing within a state, as the case of Rio Grande do Sul, there is a diversity
\end{abstract}


of situations in this sector. Therefore, this study raised empirical data in two different regions of the state, Missions and North, to identify characteristics that distinguish family farming of the two realities. The aim of the study was to identify the economic importance of subsistence activities compared to the commercial activities of family farming Dezesseis de Novembro (Region Missions) and Sertão (Northern Region) in Rio Grande do Sul, identifying heterogeneity factors in the industry. For the study were possible, we selected five representative family farming production units of the sector in each municipality. As a main result, it is emphasized that subsistence activities are developed in greater numbers and has greater economic importance, compared to commercial activities in family farming Dezesseis de Novembro than in family farming of Sertão.

Keywords: Family Farm. Subsistence. Heterogeneity. Commercialization.

\section{Participación económica de las actividades de subsistencia en la agricultura familiar}

\section{Resumen}

El presente artículo comprende un Estudio de Casos Múltiples acerca de la importancia económica de las actividades de subsistencia para la agricultura familiar de dos regiones de Rio Grande do Sul. Brasil posee características diversas cuando el asunto es agricultura. Entre esa diversidad, se destaca con importancia social y económica la agricultura familiar, la cual engloba un porcentaje significativo de la población en el campo, generando empleo y renta. Sin embargo, esta agricultura familiar es heterogénea, ya que dentro de un mismo estado, como el caso de Rio Grande do Sul, existe una diversidad de situaciones en ese sector y, de modo especial estudiado en ese trabajo, esa diversidad puede reflejar en las actividades de subsistencia y en la participación económica distinta. Para ello, este estudio levantó datos empíricos en dos distintas regiones del estado, Misiones y Norte, buscando identificar características que distinguen la agricultura familiar de las dos realidades. El objetivo del estudio fue identificar la participación económica de las actividades de subsistencia en comparación con las actividades comerciales de la agricultura familiar de Dieciséis de Noviembre (Región Misiones) y Sertão (Región Norte) en Rio Grande do Sul, identificando factores de heterogeneidad del sector. Para que el estudio fuera posible, fueron seleccionadas cinco unidades de producción agropecuarias familiares representativas del sector en cada municipio. Como principal resultado, se destaca que las actividades de subsistencia se desarrollan en mayor número y tienen mayor participación económica, si se comparan con las actividades comerciales, en la agricultura familiar de dieciséis de noviembre que en la agricultura familiar de Sertão.

Palabras clave: Agricultura Familiar. Heterogeneidad. Comercialización. Desarrollo económico

\section{Introdução}

A agricultura é um setor de importância econômica e social para o Brasil, já que gera emprego e renda no campo. Além disso, é responsável pela produção de parte dos alimentos para a população e pela geração de divisas no que se refere ao mercado internacional. Afirma-se isso, já que sem este setor não existiriam os demais elos pertencentes ao agronegócio, que colaboram com percentual significativo do Produto Interno Bruto-PIB brasileiro.

O Brasil, e especificamente o Rio Grande do Sul-RS, tem um setor agrícola que é composto, majoritariamente, pela agricultura familiar. Os dados do Censo Agropecuário de 2006 (IBGE, 2014) demonstram que a agricultura familiar no Brasil 
representa $84,4 \%$ e a não familiar, $15,6 \%$ dos estabelecimentos. Ou seja, a agricultura familiar corresponde a mais da metade dos estabelecimentos e também ocupa mais pessoas no campo, sendo $74,4 \%$ do total da população rural. No RS, Estado foco desta pesquisa, a agricultura familiar representa a maior parte das receitas em comparação com a não familiar (IBGE, 2014). As Tabelas 1 e 2 demonstram a importância da agricultura familiar em números, em nível de Brasil (Tabela 1) e do RS (Tabela 2).

Tabela 1. Agricultura familiar e agricultura não familiar no Brasil

\begin{tabular}{l|c|c}
\hline & Agricultura & $\begin{array}{c}\text { Agricultura } \\
\text { Não Familiar }\end{array}$ \\
\hline Estabelecimentos (\%) & 84,4 & 15,6 \\
Área total (\%) & 24,3 & 75,7 \\
Valor Bruto Produção (\%) & 38 & 62 \\
Valor Bruto Produção (R\$) & 89 milhões & 54 milhões \\
Pessoal Ocupado (\%) & 74,4 & 25,6 \\
Pessoal Ocupado (milhões de pessoas) & 12,3 & 4,2 \\
Valor Bruto da Produção (por área total R\$̧/há/ano) & 677 & 358 \\
Pessoal Ocupado (por área total 10o há) & 15,3 & 1,7 \\
\hline
\end{tabular}

Fonte: IBGE (2014).

Observa-se que a agricultura familiar agrega maior valor por área, bem como maior mão de obra, evidenciando a sua importância social e econômica. Essa observação ocorre tanto em nível de País quanto de Estado. É visível ainda, no RS, a importância das agroindústrias na renda e agregação de valor na agricultura familiar. Por outro lado, a terra está em maior percentual em posse da agricultura não familiar.

Tabela 2. Agricultura familiar e agricultura não familiar no Rio Grande do Sul

\begin{tabular}{lcc}
\hline & Familiar & Não Familiar \\
\hline Proporção de estabelecimentos & $86 \%$ & $14 \%$ \\
Participação do valor da produção agropecuária & $54 \%$ & $46 \%$ \\
Participação das receitas obtidas & $50 \%$ & $50 \%$ \\
Participação da agroindústria - agregar valor & $65 \%$ & $35 \%$ \\
Proporção da propriedade da terra & $31 \%$ & $69 \%$ \\
\hline
\end{tabular}

Fonte: IBGE (2014)

A agricultura familiar tem características marcantes que a diferenciam de outras agriculturas, como a empresarial e patronal, quais sejam: tem perfil distributivo e, comparada com a patronal, é melhor em termos socioculturais; trabalho e gestão intimamente relacionados; a direção do processo produtivo é assegurada diretamente pelos proprietários; ênfase na diversificação; ênfase na durabilidade dos recursos naturais e na qualidade de vida; trabalho assalariado complementar; decisões imediatas, adequadas ao alto grau de imprevisibilidade do processo produtivo; tomada de decisões in loco, condicionada pelas especificidades do processo produtivo; e ênfase no uso de insumos internos (VEIGA, 1991). Além 
disso, as unidades familiares não desaparecem frente à integração aos mercados, pois esses agricultores atuam como produtores simples de mercadorias. Dessa forma, a propriedade dos meios de produção continua relacionada às relações de parentesco (SCHNEIDER, 2003).

A agricultura familiar tem ainda uma característica essencial que é a produção de alimentos para a subsistência familiar, ou seja, sua reprodução (VEIGA, 1991; SCHNEIDER, 2003). Por outro lado, observa-se que a agricultura familiar também é heterogênea, ou seja, não se tem no Brasil e no RS uma agricultura familiar, mas muitas agriculturas familiares, cada qual com características que a diferenciam, como tecnologia, área, conhecimento, formas e meios de produção, e recursos disponíveis. Essa é uma das conclusões de Conterato e Schneider (2005) a partir de uma pesquisa de campo no RS no período de 2002/2003, nos municípios de Veranópolis, Morro Redondo, Salvador das Missões e Três Palmeiras. Essa heterogeneidade é resultante da formação histórica e cultural, condições do ambiente e políticas públicas das regiões (BATALHA; BUAINAIM; FILHO, 2005).

A abordagem de heterogeneidade demanda esforço para a análise de realidades e esse esforço tanto maior será quanto mais complexa for a realidade (CONTERATO; SCHNEIDER; WAQUIL, 2010). Considerando essa diferenciação, levanta-se a hipótese de que a produção para a subsistência também ocorre de forma diferenciada no RS. Ou seja, existem formas produtivas em que a subsistência tem papel econômico e social importante, enquanto que, em outras, a subsistência perdeu espaço para as atividades comerciais e, consequentemente, reduziu a diversificação produtiva.

No intuito de testar essa hipótese realizou-se a presente pesquisa, que teve como objetivo identificar a participação econômica das atividades de subsistência comparativamente às atividades comerciais nas regiões Missões e Norte do RS, buscando elementos de heterogeneidade da agricultura familiar no RS. Para tanto, foram comparadas duas regiões distintas do RS acerca da participação econômica da subsistência para tais realidades, sendo Dezesseis de Novembro - região Missões - e Sertão - região Norte. Para viabilizar tal pesquisa, utilizou-se como ferramenta essencial a gestão de custos rural, com a qual se mensurou quantitativamente a importância econômica das atividades de subsistência e das atividades comerciais nessas duas regiões.

\section{Produção de subsistência na agricultura na família}

Essa seção destina-se a apresentar a base teórica para a pesquisa realizada, destacando algumas discussões acerca de agricultura familiar e fatores de heterogeneidade. De um modo específico, busca-se contextualizar a produção de subsistência nesse setor.

O Brasil apresenta uma diversidade de formas produtivas na agricultura familiar, seja pela tecnologia ou pelos fatores de produção. Apresenta ainda uma combinação de atividades agrícolas e não agrícolas, bem como diferenciação nas formas de inserção ao mercado (LAMARCHE, 1993). A agricultura familiar no Brasil é extremamente heterogênea e fazem parte desse setor famílias muito pobres, até famílias com grande capital (terra, capacitação, organização, conhecimento etc.) (SOUZA FILHO et al, 2015). A utilização da categoria "agricultura familiar" é 
imprescindível para fins de política, mas é preciso reconhecer a diferenciação dos agricultores familiares. Ou seja, não basta tratá-los como únicos só por utilizarem predominantemente o trabalho familiar (SOUZA FILHO et al, 2015).

Partindo da constatação de que as diferentes regiões apresentam agricultura familiar com características distintas nas localidades que estão mais "atrasadas" no sentido do desenvolvimento, existe menor oferta de emprego agrícola, bem como de ocupações não agrícolas. Nessas regiões também se destaca a produção de subsistência. Uma produção muitas vezes financiada, em grande parte, pelas transferências socais de renda, especialmente a proveniente da aposentadoria rural e pelo trabalho das mulheres rurais, as quais se tornam empregadas domésticas na cidade. Portanto, o baixo nível de desenvolvimento rural tem uma relação com o baixo desenvolvimento das atividades não agrícolas (SILVA, 2001). Agricultores com situação econômica e fundiária de maior precariedade limitam suas atividades à produção de subsistência, consequentemente, com menor inserção na economia de mercado (ZANÜNI et al, 2000).

A fim de destacar a importância das atividades de subsistência na agricultura familiar, relata-se que esta não tem base histórica para ser considerada uma agricultura migratória, mas um sistema de produção agrícola do qual fazem parte culturas perenes, árvores frutíferas, pequenas criações, extração vegetal de produtos florestais (HURTIENNE, 2004). Por outro lado, o desafio maior da agricultura familiar para que possa contribuir para o desenvolvimento rural é ter os meios necessários que a possibilite participar de mercados dinâmicos, competitivos e exigentes em inovações (ABRAMOVAY, 1999). Ou seja, a tendência é que a agricultura familiar adquira um perfil mais direcionado a mercados específicos e segmentados. Nesse contexto, passam a ser valorizados fatores não só econômicos, como o caso da preservação ambiental, do lazer, do contato com a natureza. De um modo geral, busca-se no campo um modo e estilo de vida cada vez mais valorizado, diferente do comumente observado nas cidades (ABRAMOVAY, 1999).

Por isso, não é correto considerar como sinônimos os termos "agricultura familiar" e "produção de baixa renda", "pequena produção" ou até mesmo "agricultura de subsistência" (ABRAMOVAY, 1997). Há uma parcela importante de agricultores familiares que possui expressão econômica significativa e, em alguns casos, até majoritária comparativamente a outros tipos de agricultura (ABRAMOVAY, 1997). Considerando as distintas atividades, a produção vegetal (lavouras) é mais importante no segmento familiar, lavouras permanentes. Destacase ainda que a agricultura familiar tem maior participação na produção de pequenos animais e, mesmo dispondo de menores áreas, superava a patronal em 15 importantes produtos agropecuários. Em mais da metade de suas atividades, os rendimentos físicos (produtividade) da agricultura familiar são superiores aos da não familiar (ABRAMOVAY, 1997).

Nesse contexto, Rosa (1999, p. 2) destaca:

pode-se dizer que a agricultura familiar depara-se com realidades nem sempre promissoras como: a interpretação de que a agricultura familiar é declinante economicamente e portanto pouco importante para políticas públicas de desenvolvimento; queda real dos preços dos produtos primários, não estimulando soluções mais estruturais para o setor; 
dispersão e heterogeneidade da agricultura, limitando ou dificultando a implementação de melhorias de infraestrutura e serviços, além de maior articulação dos interesses dos agricultores; forte viés urbano, que acaba desvalorizando o meio rural e forte redução da renda agrícola nas últimas décadas; insuficiente articulação institucional em benefício da agricultura familiar, não racionalizando as diversas fontes e recursos que poderiam ser melhor direcionados para o setor; inexistência de ações de apoio à geração de renda não-agrícola no meio rural; baixo acesso dos produtores familiares à educação formal e informal e conseqüente despreparo para se inserirem em um novo contexto de alta competitividade e de busca de produtos de qualidade na produção primária.

Portanto, é imprescindível que se rompa com a identificação errônea de que agricultura familiar é sinônimo de atraso. É recorrente associar agricultura familiar a atraso econômico, tecnológico e social, que produz apenas para subsistência. Porém, essa é uma visão precipitada e que não corresponde à realidade (SOUZA FILHO et all, 2015).

Destaca-se ainda que é recorrente escutar ou ler a frase "agricultura familiar versus agronegócio", como se os termos fossem conflitantes e não pudessem coexistir no Brasil. Isso é uma incongruência, haja vista o significado conceitual dos dois termos (SILVA; BREITENBACH, 2013). Ou seja, a agricultura familiar, especialmente do RS, pertence ao agronegócio e não se opõe a este. Afirma-se isso pela origem dos conceitos e pela especificidade da agricultura familiar que, de um modo geral, é fortemente mercantilizada, inserida nos mercados e transaciona constantemente com os demais agentes do agronegócio, como o caso dos fornecedores de insumos e compradores dos produtos produzidos pelas propriedades rurais (SILVA; BREITENBACH, 2013).

É nesse contexto que o trabalho apresentado fez uma investigação para resgatar os elementos dessa heterogeneidade descrita e, especialmente, da distinta importância das atividades de subsistência. Destaca-se a importância desta pesquisa, já que são visíveis no Estado do RS algumas regiões com agricultura familiar em situação de maior precariedade e outras com nível maior de desenvolvimento. Essa heterogeneidade será explorada neste trabalho, especificamente os aspectos de produção comercial e de subsistência e suas respectivas representatividades econômicas.

\section{Método de pesquisa}

O presente artigo é resultante de uma pesquisa Quantitativa e Qualitativa. Foi utilizado o método de Estudo de Casos Múltiplos, já que se buscou realizar uma análise comparativa entre duas distintas regiões do RS. Esse comparativo pretende demonstrar a participação econômica das atividades de subsistência comparativamente às atividades comerciais na agricultura familiar de Dezesseis de Novembro e Sertão no RS.

Uma pesquisa é chamada de Estudo de Casos Múltiplos quando se estudam vários casos, enquanto no Estudo de Caso único se estuda um único caso. Os Estudos de Casos buscam profundidade de análise e cautela acerca da complexidade do fenômeno e do contexto em que ele ocorre. O objetivo da análise desse tipo não é representatividade estatística em relação a uma população. 
Embora tenha essas características, os Estudos de Casos podem ser utilizados tanto para testar quanto para construir novas teorias (YIN, 1994).

As características do Estudo de Caso são: a capacidade do pesquisador de utilizar as observações de uma única unidade ou assunto, ou caso contextual, como o ponto focal de um estudo; sua pluralidade como um método de investigação; bem como a possibilidade de combinar métodos de coleta de dados, como arquivos, entrevistas, questionários e observações (EISENHARDT, 1989). Esse método tem permitido às pesquisas transcender as fronteiras dos paradigmas tradicionais (DOOLEY, 2002).

Os casos que foram estudados na presente pesquisa tiveram por base a seleção de cinco unidades produtivas familiares no Município de Dezesseis de Novembro e cinco, em Sertão. Para a seleção das propriedades de Dezesseis de Novembro, contou-se com o auxílio de um funcionário da Prefeitura Municipal, o qual conhecia de forma ampla a realidade do município, e com dados fornecidos pela Empresa de Assistência Técnica e Extensão Rural- Emater. Em Sertão, foram selecionadas as propriedades tendo por base o conhecimento dos pesquisadores envolvidos e também com os dados fornecidos pela Emater do município.

A escolha das propriedades teve como base a necessidade de serem familiares e representativas das demais propriedades familiares do município. A seguir, é possível visualizar, na Figura 1, a localização das regiões de estudo.

Figura 1. Mapa com localização de Dezesseis de Novembro/RS e Sertão/RS

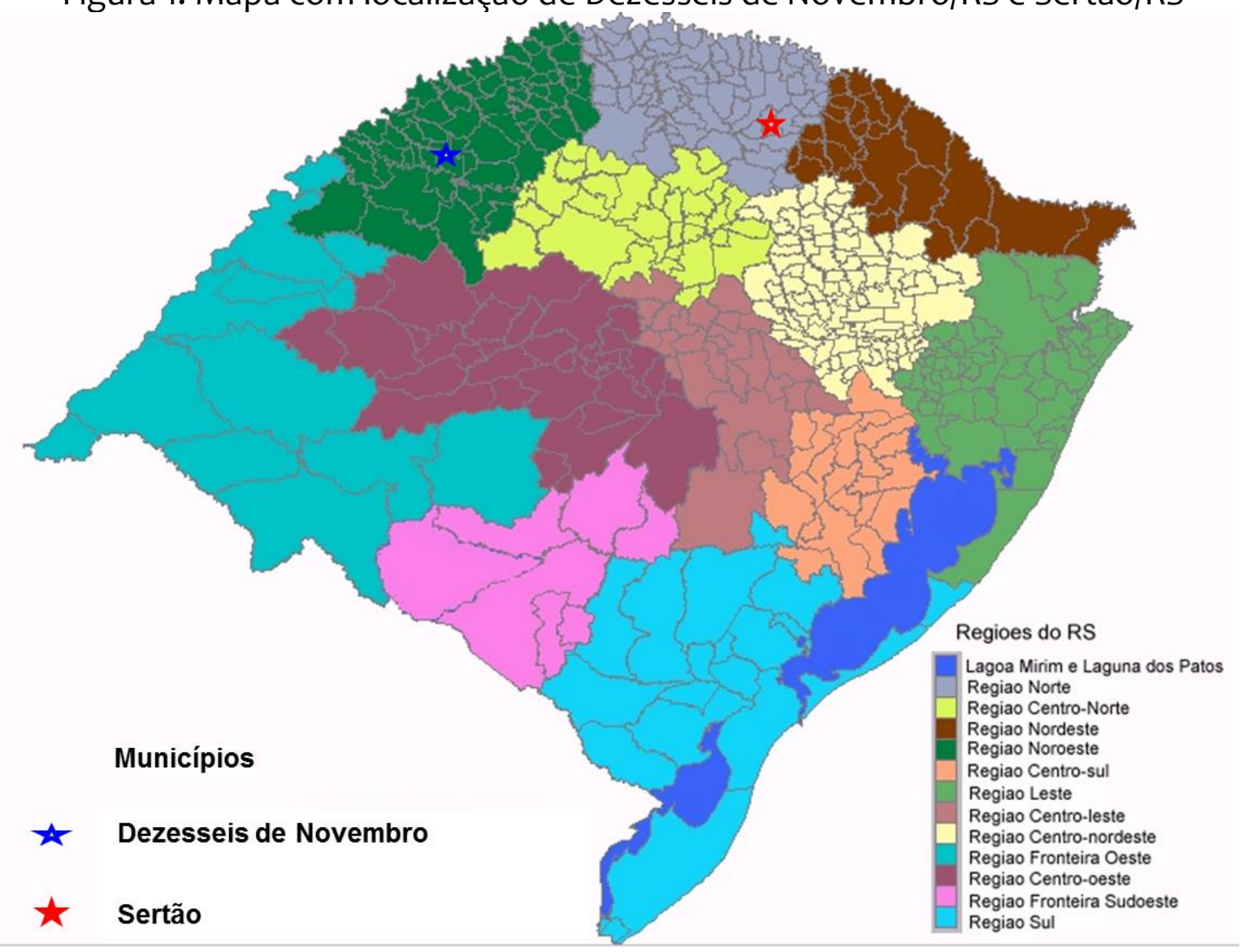

Fonte: Adaptado de NUTEP/UFRGS.

Após a definição das propriedades, o passo seguinte foi o estudo de cada unidade de produção, que foi realizado no segundo semestre de 2014. Esse Estudo 
de Casos Múltiplos compreendeu uma análise econômica detalhada dessas propriedades, destacando todas as atividades produtivas (comerciais e de subsistência), suas respectivas produções e remunerações, bem como os custos de produção.

Para a coleta dos dados empíricos mensurados, os instrumentos utilizados foram Questionário, Entrevista e Observação. Ambos os instrumentos colaboraram para a composição dos dados contábeis (especialmente o questionário) e para a compreensão das realidades e suas especificidades (com maior importância à entrevista e à observação).

Para a análise quantitativa dos dados econômicos, foi utilizada a metodologia de análise de custos desenvolvida por Lima et al (2001), denominada de Valor Agregado. Tal metodologia considera os seguintes conceitos: a) Produto Bruto-PB é tudo o que uma Unidade de Produção Agropecuária-UPA produz num ciclo agrícola (geralmente um ano) transformado em valor monetário (reais); b) Consumo Intermediário- $\mathrm{Cl}$ é o valor dos serviços e bens consumidos no decorrer do ciclo de produção, tais como: sementes, agroquímicos, combustíveis, alguma despesa com manutenção de máquinas e instalações, alimentação animal e outros, sendo tudo que é consumido no processo de produção mas não pode ser aproveitado para outro ciclo; c) Depreciação-D e respectivo Rateio é o custo que se calcula sobre as máquinas e equipamentos, instalações, o quanto cada um desses ativos fixos vai se depreciando ao longo do tempo. A Depreciação é um custo indireto. O que causa a depreciação dos bens é a ação da natureza, a forma como são utilizados e a obsolescência; d) Valor Agregado Bruto-VAB que consiste no PB descontado o Cl; e) Valor Agregado Líquido-VAL de cada atividade (VAB descontado a D); f) Distribuição do Valor Agregado-DVA e Renda Agrícola-RA. Nesta parte, são contabilizados os gastos com juros de financiamentos, o FUNRURAL - que é descontado na hora da venda do produto, arrendamento e o Imposto Territorial Rural-ITR. Por fim, do total do VAL foi descontado o DVA e se obtém um resultado de RA.

A partir dessa análise econômica detalhada, foram realizados comparativos entre as duas localidades estudadas. O comparativo estuda a participação econômica das atividades de subsistência em relação às atividades comerciais. $E$ permitiu destacar elementos contrastantes e semelhantes entre as realidades, além de identificar condicionantes da heterogeneidade da agricultura familiar no RS.

\section{Atividades produtivas comerciais e de subsistência na agricultura familiar}

Dois municípios foram incluídos na pesquisa. O primeiro deles foi Dezesseis de Novembro, na região das Missões-RS. Esse município tem uma população de 13.289 habitantes, numa área de $177,675 \mathrm{~km}^{2}$. A agricultura familiar é predominante no município. Ela tem como atividade principal a produção de alfafa (semente e feno), seguido por leite, soja e uma variedade de atividades de subsistência cujo excedente é comercializado. O segundo município estudado foi Sertão-RS, localizado na região Norte do Estado, que tem uma população de 6.294 habitantes e uma área de 439,472 km². Também em Sertão, a agricultura familiar predomina em detrimento da não familiar, sendo as atividades principais o cultivo da soja, seguido por leite, milho, trigo e demais atividades de menor importância econômica. 
A seguir serão apresentados os resultados da pesquisa empírica realizada nesses dois municípios. Inicialmente são expostos os dados empíricos obtidos na pesquisa realizada em Dezesseis de Novembro e, posteriormente, em Sertão. A discussão comparativa ocorrerá no decorrer do texto.

\subsection{Análise da importância econômica das atividades de subsistência na agricultura familiar de Dezesseis de Novembro/RS}

Destaca-se, a partir dos dados empíricos obtidos, que o município de Dezesseis de Novembro caracterizou-se - dentre as unidades de produção familiares estudadas - por ter um número maior de atividades de subsistência, conforme observado na Tabela 3. A Propriedade 1 apresentou uma atividade comercial e treze atividades de subsistência; a Propriedade 2 tem três atividades comerciais e sete de subsistência; a Propriedade 3 apresentou quatro atividades comerciais e oito de subsistência; a Propriedade 4 desenvolve uma atividade comercial apenas, sendo mais oito de subsistência; por fim, a Propriedade 5 apresentou $25 \%$ de atividades comerciais, ou seja, cinco atividades comerciais e quinze atividades de subsistência.

A média geral das unidades familiares analisadas demonstra que 0 percentual de atividades de subsistência é de $78,87 \%$ em relação ao total de atividades, variando de $66,7 \%$, na propriedade com menos atividades de subsistência, e 92,85\% na propriedade com maior proporção de atividades de subsistência.

As características observadas na região apontaram para uma maior atenção dos agricultores familiares para as atividades direcionadas à alimentação da família. Foi possível identificar que existe uma preocupação latente em manter essas atividades para auxiliar na sobrevivência dos filhos que residem na cidade, estudando ou trabalhando. É carne, leite, frutas, legumes e verduras que ajudam na redução do custo de vida dos familiares. Portanto, a preocupação desses agricultores vai além do econômico, já que estão atentos à reprodução familiar.

Tabela 3. Número e percentual de atividades comerciais e de subsistência em Dezesseis de Novembro/RS

\begin{tabular}{ccccc}
\hline Propriedade & $\begin{array}{c}\mathbf{N}^{\circ} \text { Atividades } \\
\text { Comerciais }\end{array}$ & $\begin{array}{c}\text { Atividades } \\
\text { Comerciais (\%) }\end{array}$ & $\begin{array}{c}\mathbf{N}^{\circ} \text { Atividades } \\
\text { Subsistência }\end{array}$ & $\begin{array}{c}\text { Atividades } \\
\text { Subsistência (\%) }\end{array}$ \\
\hline $\mathbf{1}$ & 1 & 7,14 & 13 & 92,85 \\
$\mathbf{2}$ & 3 & 30 & 7 & 70 \\
$\mathbf{3}$ & 4 & 33,3 & 8 & 66,6 \\
$\mathbf{4}$ & 1 & 11,1 & 8 & 89,9 \\
$\mathbf{5}$ & 5 & 25 & 15 & $\mathbf{7 5}$ \\
\hline MÉDIA & $\mathbf{2 , 8}$ & $\mathbf{2 1 , 3 7}$ & $\mathbf{1 0 , 2}$ & $\mathbf{7 8 , 8 7}$ \\
\hline
\end{tabular}

Fonte: Dados obtidos a partir da pesquisa empírica.

O foco do estudo foi identificar a participação econômica das atividades de subsistência. Dessa forma, apresenta-se, na Tabela 4, a representatividade em valores monetários das atividades comerciais e de subsistência. Observa-se que, 
embora o número de atividades de subsistência seja significativamente maior, o valor comercial das mesmas é inversamente menor. Isso ocorre tanto para os valores de $\mathrm{PB}$, que correspondem ao total produzido multiplicado pelo preço de venda (para atividades comerciais) ou pelo preço de mercado praticado na propriedade rural (para atividades de subsistência); quanto para o VAL, que são os valores de PB descontado os custos de produção e a depreciação.

Tabela 4. Valores referentes às atividades comerciais e de subsistência em Dezesseis de Novembro/RS

\begin{tabular}{ccccc}
\hline Propriedade & $\begin{array}{c}\text { Produto Bruto-PB }{ }^{2} \\
\text { Atividades } \\
\text { Comerciais (R\$) }\end{array}$ & $\begin{array}{c}\text { Produto Bruto-PB } \\
\text { Atividades } \\
\text { Subsistência (R\$) }\end{array}$ & $\begin{array}{c}\text { Valor Agregado } \\
\text { Bruto-VAL } \\
\text { Atividades } \\
\text { Comerciais (R\$) }\end{array}$ & $\begin{array}{c}\text { Valor Agregado } \\
\text { Bruto-VAL } \\
\text { Atividades } \\
\text { Subsistência (R\$̦) }\end{array}$ \\
\hline $\mathbf{1}$ & $11.812,50$ & $2.805,13$ & $3.086,43$ & $1.599,51$ \\
$\mathbf{2}$ & $55.500,00$ & $9.900,00$ & $25.835,91$ & 365,87 \\
$\mathbf{3}$ & $15.200,40$ & $7.980,00$ & $7.702,10$ & 990,40 \\
$\mathbf{5}$ & $37.800,00$ & $16.167,50$ & $30.880,50$ & $11.270,6$ \\
\hline MÉDIA & $50.630,00$ & $10.048,50$ & $39.234,93$ & $5.101,85$ \\
\hline
\end{tabular}

Fonte: Dados obtidos a partir da pesquisa empírica.

Essa afirmação fica mais visível quando a análise é feita tendo por base os valores em percentual, como mostra a Tabela 5. Observa-se que o PB tem origem, majoritariamente, nas atividades comerciais, sendo $76,95 \%$. Por outro lado, as atividades de subsistência que são em maior número, contribuem em média com 23,05\%. Os valores se apresentam com diferenciação significativa também quando analisado o VAL, sendo de $77,31 \%$ e $22,69 \%$ para as atividades comerciais e de subsistência, respectivamente.

Tabela 5. Percentuais de participação das atividades referente ao Valor Agregado Bruto e Produto Bruto em Dezesseis de Novembro/RS

\begin{tabular}{ccccc}
\hline Propriedade & $\begin{array}{c}\text { Produto Bruto- } \\
\text { PB }^{1} \text { Atividades } \\
\text { Comerciais (\%) }\end{array}$ & $\begin{array}{c}\text { Produto Bruto-PB } \\
\text { Atividades } \\
\text { Subsistência (\%) }\end{array}$ & $\begin{array}{c}\text { Valor Agregado } \\
\text { Bruto-VAL } \\
\text { Atividades } \\
\text { Comerciais (\%) }\end{array}$ & $\begin{array}{c}\text { Valor Agregado } \\
\text { Bruto-VAL } \\
\text { Atividades } \\
\text { Subsistência (\%) }\end{array}$ \\
\hline $\mathbf{1}$ & 80,81 & 19,19 & 65,87 & 34,13 \\
$\mathbf{2}$ & 84,86 & 15,14 & 98,60 & 1,40 \\
$\mathbf{4}$ & 65,57 & 34,43 & 88,61 & 11,39 \\
$\mathbf{5}$ & 70,04 & 29,96 & 73,26 & 26,74 \\
\hline MÉDIA & 83,44 & 16,56 & 88,49 & 11,51 \\
\hline
\end{tabular}

Fonte: Dados obtidos a partir da pesquisa empírica.

Existe uma dedicação importante dos agricultores de Dezesseis de Novembro em manter a segurança alimentar de sua família. Seja com diversidade de alimentos produzidos em nível de propriedade, bem como por considerar esses alimentos mais saudáveis do que os adquiridos nos supermercados. O centro dessa preocupação tem uma relação direta com o valor essencial dado à possibilidade de 
manter os filhos com os produtos produzidos em nível local, ou seja, nas unidades de produção familiares.

Destaca-se, ainda, que essas famílias não têm intenção de substituir atividades de subsistência por atividades comerciais, mesmo as que têm conhecimento da potencialidade financeira que isso tem. Um dos fatores relacionados a essa decisão diz respeito às características de clima da região, já que a escassez de precipitação é recorrente, fazendo com que o investimento em outras atividades comerciais tenha um risco significativo. Esse risco é aumentado pelo baixo conhecimento gerencial que os agricultores entrevistados possuem.

\subsection{Análise da importância econômica das atividades de subsistência na agricultura familiar de Sertão/RS}

Essa etapa da análise se destina a apresentar os dados obtidos a partir do estudo de casos múltiplos das unidades de produção selecionadas no Município de Sertão/RS. Ao selecionar as unidades de produção agropecuárias para participarem da pesquisa, foram priorizadas as que fossem mais representativas da região.

No período de coleta de dados e observação, já foi possível identificar diferença entre as duas regiões analisadas. Essa diferença é em relação à área, à tecnologia empregada nas atividades, às próprias atividades desenvolvidas, ao clima, aos recursos financeiros, e, especificamente, à participação econômica das atividades de subsistência na renda total da propriedade.

A Tabela 6 apresenta o número de atividades de subsistência e de atividades comerciais desenvolvidas. Comparativamente com a região das Missões, o número de atividades de subsistência é significativamente menor na região Norte, enquanto que o número de atividades comerciais é sensivelmente maior. Quando a análise é percentual, a diferença também fica evidente, sendo que as atividades comerciais correspondem à maioria, sendo $57,42 \%$.

Tabela 6. Valores referentes às atividades comerciais e de subsistência em Sertão/RS

\begin{tabular}{ccccc}
\hline Propriedade & $\begin{array}{c}\mathbf{N}^{\circ} \text { Atividades } \\
\text { Comerciais }\end{array}$ & $\begin{array}{c}\text { Atividades } \\
\text { Comerciais (\%) }\end{array}$ & $\begin{array}{c}\mathbf{N}^{\circ} \text { Atividades } \\
\text { Subsistência }\end{array}$ & $\begin{array}{c}\text { Atividades } \\
\text { Subsistência (\%) }\end{array}$ \\
\hline $\mathbf{1}$ & 4 & 66,66 & 2 & 33,3 \\
$\mathbf{2}$ & 2 & 40 & 3 & 60 \\
$\mathbf{3}$ & 4 & 57,14 & 3 & 42,85 \\
$\mathbf{4}$ & 2 & 40 & 3 & 60 \\
$\mathbf{5}$ & 5 & 83,3 & 1 & 16,7 \\
\hline MÉDIA & 3,4 & 57,42 & 2,4 & 42,57 \\
\hline
\end{tabular}

Fonte: Dados obtidos a partir da pesquisa empírica.

Apesar de presentes, as atividades de subsistência têm baixa participação econômica, comparativamente às atividades comerciais, como observado na Tabela 7. Das cinco unidades de produção familiares analisadas, três delas apresentaram retorno financeiro VAL negativo para essas atividades.

Se consideradas apenas as duas propriedades em que o VAL da subsistência foi positivo, tem-se uma variação da contribuição entre elas. Numa, o VAL foi R\$ 
2.375,40 e, em outra, foi de $\mathrm{R} \$$ 360,33. Mesmo demonstrando esses valores positivos, eles são baixos se comparados aos valores das atividades comerciais, que são de $\operatorname{R}$ 217.300,00 e $\mathrm{R} \$$ 472.000,00, respectivamente para essas duas propriedades.

Tabela 7. Valores referentes às atividades comerciais e de subsistência em Sertão/RS

\begin{tabular}{ccccc}
\hline Propriedade & $\begin{array}{c}\text { Produto Bruto-PB } \\
\text { Atividades } \\
\text { Comerciais (R\$) }\end{array}$ & $\begin{array}{c}\text { Produto Bruto-PB } \\
\text { Atividades } \\
\text { Subsistência (R\$) }\end{array}$ & $\begin{array}{c}\text { Valor Agregado } \\
\text { Bruto-VAL } \\
\text { Atividades } \\
\text { Comerciais (R\$̣) }\end{array}$ & $\begin{array}{c}\text { Valor Agregado } \\
\text { Bruto-VAL } \\
\text { Atividades } \\
\text { Subsistência (R\$) }\end{array}$ \\
\hline $\mathbf{1}$ & $494.300,00$ & $5.200,00$ & $237.948,01$ & $-3.395,71$ \\
$\mathbf{2}$ & $89.000,00$ & 1810,00 & $45.488,60$ & $-3.675,73$ \\
$\mathbf{3}$ & $217.300,00$ & 5140,00 & $115.214,88$ & $2.375,40$ \\
$\mathbf{4}$ & $472.000,00$ & $2.825,00$ & $251.914,07$ & 360,33 \\
$\mathbf{5}$ & $314.737,50$ & $3.300,00$ & $128.886,66$ & $-500,00$ \\
\hline MÉ́nIA & $314.737,50$ & $3.300,00$ & $128.886,66$ & $-500,00$ \\
\hline
\end{tabular}

Fonte: Dados obtidos a partir da pesquisa empírica.

Quando a análise é percentual (Tabela 8), a diferença fica mais aparente. Observa-se que o percentual de participação na renda das atividades de subsistência é negativo em (-)1,69\%. Por outro lado, a variação existente entre as propriedades aproxima-se dos $10 \%$, sendo de (-) $8,79 \%$ do menor VAL Subsistência até $2,02 \%$ o maior VAL Subsistência.

Tabela 8. Percentuais de participação das atividades referente ao Valor Agregado Bruto e Produto Bruto em Sertão/RS

\begin{tabular}{ccccc}
\hline Propriedade & $\begin{array}{c}\text { Produto Bruto-PB } \\
\text { Atividades } \\
\text { Comerciais (\%) }\end{array}$ & $\begin{array}{c}\text { Produto Bruto-PB } \\
\text { Atividades } \\
\text { Subsistência (\%) }\end{array}$ & $\begin{array}{c}\text { Valor Agregado } \\
\text { Bruto-VAL } \\
\text { Atividades } \\
\text { Comerciais (\%) }\end{array}$ & $\begin{array}{c}\text { Valor Agregado } \\
\text { Bruto-VAL Atividades } \\
\text { Subsistência (\%) }\end{array}$ \\
\hline 1 & 98,96 & 1,04 & 101,45 & $-1,45$ \\
2 & 98,01 & 1,99 & 108,79 & $-8,79$ \\
3 & 97,69 & 2,31 & 97,98 & 2,02 \\
4 & 99,41 & 0,59 & 99,86 & 0,14 \\
5 & 98,96 & 1,04 & 100,39 & $-0,39$ \\
\hline MÉDIA & 98,60 & 1,40 & 101,69 & $-1,69$ \\
\hline
\end{tabular}

Fonte: Dados obtidos a partir da pesquisa empírica.

A baixa produção para o auto consumo, ou subsistência, demonstra que nem - Programa Nacional de Fortalecimento da Agricultura Familiar-Pronaf, nem iniciativas locais, estão conseguindo interferir e instigar os agricultores familiares a retomar a produção para subsistência. Ao contrário disso, as políticas públicas e as iniciativas locais reforçam o padrão produtivista em detrimento da diversificação de estratégias de vivência e de desenvolvimento rural (GAZOLLA, 2004). Porém, as atividades de subsistência contribuem com a autonomia familiar, a sociabilidade comunitária e interfamiliar, o compartilhamento de saberes entre agricultores e 
para a segurança alimentar das famílias (GAZOLLA; SCHNEIDER, 2007). Contribui ainda, para a internalização de recursos e tarefas, para a diversificação dos meios de vida, para a estabilidade socioeconômica, traz economias de recursos financeiros (compras em mercado), potencializa recursos ociosos (maquinários, áreas, mão de obra), pode auxiliar no consumo familiar ao mesmo tempo em que pode se tornar valor de troca, e tem relação com a identidade dos agricultores (GRISA, 2007).

\section{Considerações finais}

A pesquisa realizada corrobora a afirmativa da heterogeneidade da agricultura familiar no Estado do Rio Grande do Sul, destacando aspectos específicos referentes à importância/participação econômica das atividades de subsistência no total da renda e lucro das propriedades, comparativamente com as atividades comerciais. Concluiu-se que no Município de Dezesseis de Novembro, localizado na região das Missões, a subsistência tem uma importância maior se comparado ao Município de Sertão, Norte do Estado. Essa importância e participação se referem em número de atividades e aos valores comerciais, tanto de PB quanto de VAL.

Quando resgatado o objetivo do estudo, que era identificar a participação/importância econômica das atividades de subsistência comparativamente com as atividades comerciais na agricultura familiar de Dezesseis de Novembro e Sertão no Rio Grande do Sul, identificando fatores de heterogeneidade do setor, foi possível verificar que o objetivo foi alcançado. Concluiu-se, portanto, que o fato dos agricultores familiares de Dezesseis de Novembro terem mais atividades de subsistência, e estas terem mais participação econômica que os agricultores familiares de Sertão, são indicativos da heterogeneidade da agricultura familiar gaúcha.

Como limitação da pesquisa, alerta-se para o método utilizado, que foi o Estudo de Casos Múltiplos. Para essa metodologia, as generalizações de resultados não são indicadas e, portanto, os dados empíricos encontrados e conseguintes discussões limitam-se às realidades estudadas. Mesmo os pesquisadores tendo fortes indícios, a partir dos casos representativos estudados, que os levem a acreditar que as demais realidades das regiões sejam iguais, o método escolhido limita afirmações nesse sentido. Por outro lado, ressalta-se que dentro da proposta da pesquisa, que foi estudar em profundidade essas unidades de produção, o método de Estudo de Casos Múltiplos é adequado e cumpriu com a especificidade da pesquisa, sendo suficiente para alcançar o objetivo proposto.

Destaca-se que outras diferenciações ainda poderiam ser exploradas, como o caso das especificidades regionais de clima, solo, tecnologia, cultura, educação, recursos produtivos, área disponível, recursos financeiros, entre outros. As diferenciações são visíveis e percebe-se que a região onde se localiza Dezesseis de Novembro possui recursos mais limitados para as atividades, além de problemas como escassez de chuva frequente, que se reflete em maior pobreza.

\section{REFERÊNCIAS}


ABRAMOVAY, R. Agricultura familiar e uso do solo. São Paulo em Perspectiva Abr/jun, vol. 11, n²:73-78, 1997.

ABRAMOVAY, R. Agricultura familiar e desenvolvimento territorial. Reforma Agrária - Revista da Associação Brasileira de Reforma Agrária - vols. 28 ns 1,2 3 e 29, nº 1 Jan/dez 1998 e jan/ago 1999.

BATALHA, M. O.; BUAINAIN, A. M.; SOUZA FILHO, H. M. de. Tecnologia de gestão e agricultura familiar. 2005. p. 1-19. Disponível em:

http://www2.ufersa.edu.br/portal/view/uploads/setores/241/Tecnologia\%20de\%20Ge st\%C3\%A30\%20e\%20Agricultura\%20Familiar.pdf. Acesso em: 22 ago. 2014.

BRASIL. Lei $\mathbf{N}^{\circ}$ 11.326, de 24 de julho de 2006. Disponível em: http://www.planalto.gov.br/ccivil_03/_ato2004-2006/2006/lei/l11326.htm. Acesso em: 30 out. 2014

CONTERATO, M. A.; SCHNEIDER, S.; WAQUIL, P. D. Estilos de agricultura: uma perspectiva para a análise da diversidade da agricultura familiar. Ensaios FEE. Porto Alegre. v. 31. n. 1, 2010, p. 149-186. Disponível em: http://www.ufrgs.br/pgdr/arquivos/777.pdf. Acesso em: 22 ago. 2014.

CONTERATO, M. A.; SCHNEIDER, S. Tipos de pluriatividade na agricultura familiar e desenvolvimento rural. p. 1-22. 2005. Disponível em: http://www.sober.org.br/palestra/2/643.pdf. Acesso em: 23 set. 2014.

DOOLEY, L. M. Case Study Research and Theory Building. In: SWANSON, R. A. \& HOLTON, E. F. III (Eds.), Research in organizations: Foundations and methods of inquiry (pp. 327-350). San Francisco, CA: Berrett-Koehler. 2002.

EISENHARDT, K. M. Building Theories from Case Study Research. Academy of Management Review, v. 14. n. 4, 532-550, 1989.

FONTOURA, A. F. da et al. Tipologias dos estabelecimentos rurais do município de Paraíso do Sul. s/d. Disponível em:

http://coral.ufsm.br/desenvolvimentorural/textos/Artigo\%20Uergs\%20\%2opronto..pdf. Acesso em: 28 out. 2014.

GAZOLLA, M. Agricultura Familiar, Segurança Alimentar e Políticas Públicas: Uma análise a partir da produção para autoconsumo no território do Alto Uruguai/RS. Universidade Federal do Rio Grande do Sul, Programa de Pós-Graduação em Desenvolvimento Rural. Dissertação de Mestrado. Porto Alegre, 2004.

GAZOLLA, M.; SCHNEIDER, S. A produção da autonomia: os "papéis" do autoconsumo na reprodução social dos agricultores familiares. Capa, Ano 15 volume 01, abril a setembro 2007. 
GRISA, C. para além da alimentação: papéis e significados da produção para autoconsumo na agricultura familiar. Revista Extensão Rural, DEAER/CPGExR - CCR - UFSM, Ano XIV, Jan - Dez de 2007.

HURTIENNE, T. Análise socioeconômica dos sistemas de uso de terra por pequenos produtores agrários na Amazônia Oriental. Novos Cadernos NAEA, v. 7, n. 2, p. 191$272,2004$.

IBGE - Instituto Brasileiro de Geografia e Estatística. Censo Agropecuário 2006. Disponível em:

http://www.ibge.gov.br/home/estatistica/economia/agropecuaria/censoagro/2006/d efault. Acesso em: 19 dez. 2014.

LAMARCHE, H. A agricultura familiar: comparação internacional. Tradução: Ângela Maria Naoko Tijiwa. Campinas, SP: Editora da UNICAMP, 1993.

LIMA, A. J. P. de. et. al. Administração da unidade de produção familiar: modalidades de trabalho com agricultores. 2. ed. Ijuí: UNIJUÍ, 2001.

YIN, R. K. Case study research: design and methods. 2. ed. California: Sage Publications, 1994.

ROSA, S. L. C. Agricultura familiar e desenvolvimento local sustentável. Texto apresentado no $37^{\circ}$ Congresso Brasileiro de Economia e Sociologia Rural-SOBER, em Fóz do Iguaçu, em agosto de 1999. Disponível em:

http://www.incra.gov.br/sites/default/files/uploads/servicos/publicacoes/outraspublicacoes/agricfamiliardesenvolvlocalsustentavel.pdf. Acesso em: 20 mai. 2015.

SCHNEIDER, S. Teoria social, agricultura familiar e pluriatividade. Rev. Bras. Ci. Soc. n. 51. p. 99-192. fev. 2003.

SILVA, A.; BREITENBACH, R. O debate "agricultura familiar versus agronegócio": as jaulas ideológicas prendendo os conceitos. Revista Extensão Rural, DEAER- CCR UFSM, vol.20 n², mai - ago de 2013.

SILVA, J. G. da. Velhos e novos mitos do rural brasileiro. Estudos Avançados. v. 15. n. 43,2001

SOUZA FILHO, H. M. de.; BUAINAIN, A. M.; GUANZIROLI, A. M.; BATALHA, M. O. Agricultura Familiar e Tecnologia no Brasil: características, desafios e obstáculos. Acesso em: http://www.sober.org.br/palestra/12/090442.pdf. Acesso em: 18 fev. 2015.

VEIGA, J. E. O desenvolvimento agrícola. São Paulo: Hucitec/Edusp, 1991.

ZANÜNL, M. M.; FERREIRA, A. D. D.; MIGUEL, L. A. de. Preservação da natureza e desenvolvimento rural: dilemas e estratégias dos agricultores familiares em Áreas 
de Proteção Ambiental. Desenvolvimento e Meio Ambiente. n. 2. p. 39-55, jul.Idez. Editora da UFPR. 2000.

Raquel Breitenbach. Professora Doutora no Instituto Federal de Educação, Ciência e Tecnologia do Rio Grande do Sul. raquel.breitenbach@sertao.ifrs.edu.br. 